
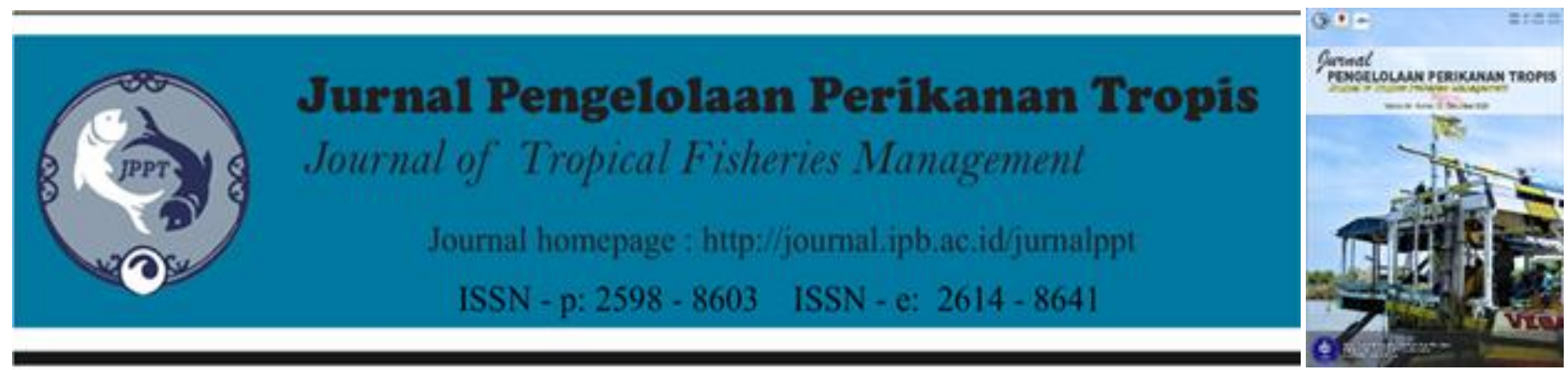

\title{
Kerentanan Bycatch Tuna dari Perikanan Handline di Selatan Samudera Hindia: Pencatatan Pelabuhan Sendang Biru-Malang
}

\author{
(The Vulnerability of Bycacth Tuna of Handline Fishing in Southern Indian Ocean: Recorded in Sendang \\ Biru Landing Port-Malang)
}

\section{Yonvitner $^{1,2, *}$, Mennofatria Boer ${ }^{1}$, Rahmat Kurnia ${ }^{1}$, Helmi Akbar ${ }^{3}$, Surya Gentha Akmal ${ }^{4}$}

${ }^{1}$ Divisi Manajemen Sumberdaya Perikanan, Departemen Manajemen Sumberdaya Perairan-Fakultas Perikanan dan Ilmu Kelautan IPB

${ }^{2}$ Center for Coastal and Marine Resources Studies

${ }^{3}$ Program Studi Manajemen Sumberdaya Perairan, Universitas Mulawarman

${ }^{4}$ Doctoral Program di Chzech University of Life Science, Republik Ceko

\section{INFO ARTIKEL}

Histori Artikel

Recevied: 10 Oktober 2020

Accepted: 31 Desember 2020

\section{Kata Kunci:}

bycatch, kerentanan, produktivitas, Sendangbiru, susceptabilitas Keywords:

bycatch, productivity, Sendang Biru, susceptability, vulnerability

\section{Korespondensi Author} Yonvitner,

Divisi Manajemen Sumberdaya Perikanan, Departemen Manajemen Sumberdaya Perairan-Fakultas Perikanan dan Ilmu Kelautan IPB. Email: yonvitr@yahoo.com

\begin{abstract}
ABSTRAK
Bycatch tuna merupakan komoditas ikan komersial penting dalam perikanan tuna Samudera Hindia. Aktivitas penangkapan bycatch tuna juga berdampak pada penurunan stok sehingga menjadi rentan dan potensial tidak berkelanjutan. Penelitian ini bertujuan menganalisis tingkat kerentanan ikan tangkap samping tuna, yang dilakukan di Sendangbiru Malang pada Bulan Juli 2013. Analisis kerentanan dengan pendekatan jarak Euclidean dengan data produkitivitas dan susceptabilitas menggunakan software PSA. Hasil tangkap bycacth tuna adalah ikan cakalang (Katsuwonus pelamis), ikan lemadang (Coryphaena hippurus), baby tuna (Thunnus albacores). Hasil analisis kerentanan menunjukan tingkat kerentanan yang diperoleh sebesar 1,66 untuk baby tuna, 1,27 untuk lemadang dan 1,42 untuk cakalang. Secara keseluruhan nilai indek kerentanan masih rendah dari 1,8 dimana stok tergolong rentan rendah dan potensi ikan bycatch tuna masih berpotensi berkelanjutan dan tidak mengarah overfishing.
\end{abstract}

\section{ABSTRACT}

Bycatch tuna is an important commercial fish commodity in the Indian Ocean tuna fishery. Tuna bycatch fishing activity also has an impact on the decline in stocks, making it vulnerable and potentially unsustainable. This study aims to analyze the level of vulnerability of tuna side-caught fish, which was conducted in Sendangbiru Malang in July 2013. Vulnerability analysis using the Euclidean distance approach with productivity and susceptability data using PSA software. The catch of bycacth tuna is skipjack tuna (Katsuwonus pelamis), lemadang fish (Coryphaena hippurus), baby tuna (Thunnus albacores). The results of the vulnerability analysis showed that the level of vulnerability obtained was 1.66 for baby tuna, 1.27 for lemadang and 1.42 for skipjack. Overall, the vulnerability index value is still low from 1.8 where the stock is classified as low susceptibility and the potential for tuna bycatch is still potentially sustainable and does not lead to overfishing.

\section{PENDAHULUAN}

Ikan tuna merupakan kelompok hight migratory species (spesies yang bermigrasi jauh), dan berperan penting dalam perdagangan ikan dunia. Hasil tangkapan ikan tuna Indonesia pada tahun 2009 sekitar 5\% dari total tangkapan ikan laut dunia (Sunoko and Huang, 2014). Produksi ikan tuna bersumber dari Samudera Pasifik $68 \%$ dan Samudera Hindia sekitar 22\% dan sisanya $10 \%$ dari Samudera Atlantik dan Laut Mediterania. Adapun komposisi ikan tuna yang tertangkap meliputi cakalang (skipjack tuna) 60\%, madidihang (yellow fin tuna) $24 \%$, big eye $10 \%$, 
dan Albacore 5\%, sisanya tuna sirip biru sekitar 1\%. Sunoko and Huang (2014) mencatat komposisi skipjack 7,27\%, baby tongkol 8,09\%. Faktanya dalam perikanan tuna hasil tangkap bycatch seringkali lebih tinggi komposisinya. Kondisi inilah yang kemudian dapat menyebabkan tingginya resiko kerentanan.

Peningkatan produksi tuna tersebut terjadi akibat peningkatan kebutuhan penduduk dunia dan perubahan preferensi konsumen dunia dari red meat ke white meat. Disamping itu peningkatan juga dikarenakan berkembangnya alat tangkap jaring (purse seine), sebagai salah satu alat alternatif baru selain pancing (hook and line). Penggunaan alat tangkap baru tersebut memicu tingkat eksploitasi yang tinggi yang akhirnya menyebabkan penurunan sumberdaya (stock) dihampir semua perairan. Penangkapan bycatch menjadi tinggi karena hampir $60 \%$ tuna sudah full exploitation dan $35 \%$ over exploited (Sunoko and Huang, 2014).

Permintaan yang tinggi di pasar internasional dan intensitas yang juga meningkat, mendorong meningkatnya tingkat keterancaman perikanan tuna termasuk baycatch tuna. Selain itu keterancaman juga dapat meningkat karena teknik penangkapan. Keterancaman perikanan baycacth tuna dievaluasi dari indikator produktivitas dan suceptabilitas. Produktivitas (productivity) mengacu pada kemampuan untuk pulih secara cepat ketika stoknya berkurang, sementara keterancaman (susceptibility) adalah potensi dipengaruhinya stok oleh adanya aktivitas penangkapan. Hubungan kedua parameter ini kemudian memberikan informasi tentang kerentanan stok ikan (Yonvitner, 2020). Kajian kerentanan saat ini banyak dikembangkan juga dalam kaitanya dengan ketertelusuran produk ikan hasil tangkapan. Biasanya pasar internasional mensyaratkan hasil tangkapan yang ramah lingkungan dan tidak menyebabkan risiko yang mengancam keberlanjutan.

Pendekatan dengan atribut productivitiy dan suceptability juga sudah diujikan pada beberapa jenis seperti tropical eel (Yonvitner, 2017a), ikan pelagis kecil (Puspita et al., 2017) yang batasanya sudah direview sesuai ikan pelagis kecil untuk wilayah tropis (Yonvitner, 2017b). Namun karena dalam praktek perikanan tuna, baycacth juga selalu ditangkap, maka dikhawatirkan akan menjadi rentan dan mengganggu keberlanjutannya. Untuk itu penelitian ini bertujuan mengkaji tingkat keterancaman perikanan baycatch tuna, serta memberikan rekomendasi kebijakan perikanan tuna berdasarkan hasil penelitian berbasis data produktivitas dan suceptabilitas.

\section{METODE}

\section{Lokasi Penelitian}

Penelitian dilaksanakan pada 4 - 29 Juli 2013 di PPP Sendang Biru Malang. Data ikan tuna dan bycatch merupakan hasil tangkapan nelayan dari perairan Selatan Jawa Samudera Hindia (WPP 573). Daerah penangkapan nelayan tuna sendang biru berdasarkan sebaran geografis sebagian besar diselatan jawa seperti disajikan pada Gambar 1.

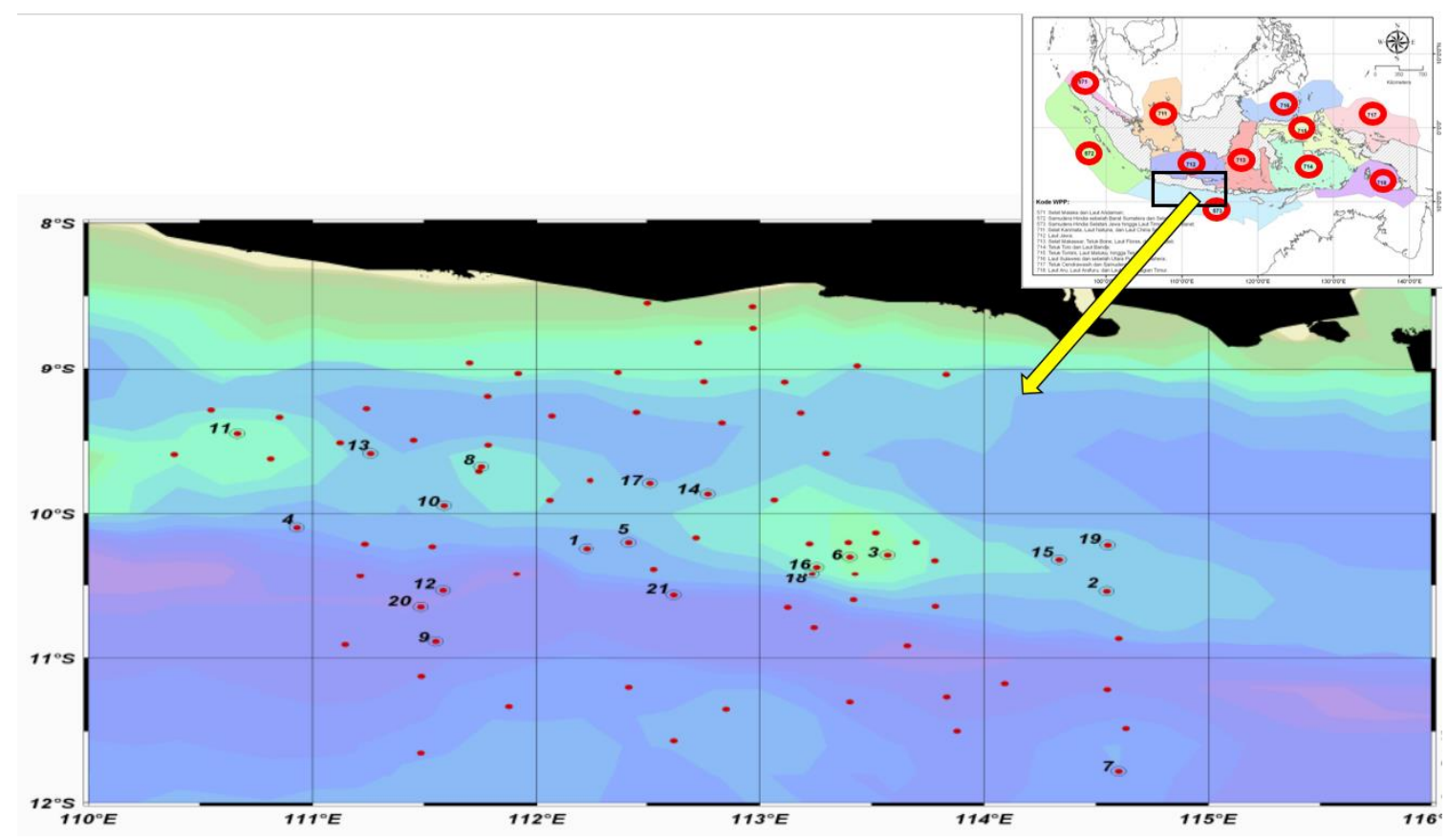

Gambar 1. Lokasi penangkapan ikan (Sumber: Hermawan et al., 2012 dan KKP 2014) 
Data yang dikumpulkan adalah data ukuran ikan, reproduksi, dinamika populasi, serta strategi pemijahan. Kemudian data lainya yaitu data produksi, upaya tangkap, kondisi sosial ekonomi, fishing ground, ekosistem diperoleh dari catatan pengumpul tuna, eksportir, riset lainya, dan sumber wawancara. Ikan tangkapan samping perikanan tuna diidentifikasi dengan cepat (rapid assessment), kemudian dilakukan pengambilan contoh secara acak untuk masing-masing spesies berdasarkan ukuran ikan, jumlah ikan yang mewakili. Kemudian masing-masing jenis ikan diukur panjang dan bobot, kemudian di bedah untuk analisis fekunditas dan makanan.
Pengamatan laboratorium dilakukan pada Laboratorium biologi perikanan IPB.

Analisis

Analisis kerentanan menggunakan pendekatan multikriteria yang dilakukan secara kualitative dari dua atribut utama yaitu produktivitas dan suceptabilitas. Atribut produktivitas memiliki 10 parameter utama yang dikaji datanya, dan atribut suceptabilitas sebanyak 12 parameter. Analisis gabungan menggunakan pendekatan jarak (Euclidean Distance). Parameter yang analisis tersebut seperti pada Tabel 1 .

Tabel 1. Parameter produktivitas dan suceptabilitas

\begin{tabular}{|c|c|c|c|}
\hline Parameter Produktivitas & Jenis Data & Analysis & Pengumpulan data \\
\hline $\begin{array}{l}\text { Pertumbuhan Instrisik (Intrinsic } \\
\text { growth) }\end{array}$ & Produksi dan Upaya & Growth Analysis & In-situ \\
\hline Umur Maksimum (Max age) & Panjang & Length frequency analysis & In-situ \\
\hline Ukuran Maksimum (Max size) & Panjang & Length frequency analysis & In-situ \\
\hline $\begin{array}{l}\text { Lanju pertumbuhan/K (Growth } \\
\text { coefficient) }\end{array}$ & Panjang & Bartalannfy & In-situ \\
\hline $\begin{array}{l}\text { Kematian alami/M (Natural } \\
\text { mortality) }\end{array}$ & Panjang & Persamaan empiric Pauly & In-situ \\
\hline Fekunditas (Fecundity) & Telur ikan & Gravimetrik dan volumetrik & In-situ and Ex-situ \\
\hline $\begin{array}{l}\text { Strategy pemijahan (Breeding } \\
\text { strategy) }\end{array}$ & Diameter telur & Cohort analysis & In-situ and Ex-situ \\
\hline Pola recruitment (Rekruitmet pattern) & Length frekuensi & Normsep and Gausian distribution & In-situ \\
\hline $\begin{array}{l}\text { Umur saat matang gonad (Age at } \\
\text { Maturity) }\end{array}$ & Length dan Diameter telur & Length frequency analysis & In-situ \\
\hline $\begin{array}{l}\text { Rata-rata tropic level (Mean tropic } \\
\text { level) }\end{array}$ & Makanan & $\begin{array}{l}\text { Niche overlap (Simpson and } \\
\text { Jaccard index) }\end{array}$ & In-situ \\
\hline Parameter Seceptability & Jenis Data & Analysis & Pengumpulan data \\
\hline Tumpang tindih area (Area overlap) & Distribusi & Distribusi & $\begin{array}{l}\text { In-situ/ } \\
\text { Quisioner }\end{array}$ \\
\hline $\begin{array}{l}\text { Daerah Sebaran geografis } \\
\text { (Concentrasi geografis) }\end{array}$ & Distribusi & Distribusi & $\begin{array}{l}\text { In-situ/ } \\
\text { Quisioner }\end{array}$ \\
\hline $\begin{array}{l}\text { Tumpang tindih vertical (Vertical } \\
\text { overlap) }\end{array}$ & Distribusi & Dsitribusi & $\begin{array}{l}\text { In-situ/ } \\
\text { Quisioner }\end{array}$ \\
\hline $\begin{array}{l}\text { Rasio Mortalitas fishing terhadap } \\
\text { alami (F / M) }\end{array}$ & Length Data & Persamaan Pauly dan Evanof & In-situ \\
\hline $\begin{array}{l}\text { Biomass stok pemijahan SSB } \\
\text { (spawning stock biomass) }\end{array}$ & Biomass Hasil tangkapan & Ricker & In-situ \\
\hline $\begin{array}{l}\text { Migrasi musiman (Seasonal } \\
\text { migration) }\end{array}$ & Data Migrasi & Pola Distribusi & $\begin{array}{l}\text { In-situ/ } \\
\text { Quisioner }\end{array}$ \\
\hline $\begin{array}{l}\text { Kelompok Berkumpul (Schooling } \\
\text { aggregation) }\end{array}$ & Schooling & Pola Distribusi & $\begin{array}{l}\text { In-situ/ } \\
\text { Quisioner }\end{array}$ \\
\hline $\begin{array}{l}\text { Efek morphologi (Morfology } \\
\text { affecting) }\end{array}$ & Morfology & Morfologis & $\begin{array}{l}\text { In-situ/ } \\
\text { Quisioner }\end{array}$ \\
\hline $\begin{array}{l}\text { Kemampuan hidup setelah } \\
\text { penangkapan (Survival after Capture) }\end{array}$ & Morfology & Morfologis & $\begin{array}{l}\text { In-situ/ } \\
\text { Quisioner }\end{array}$ \\
\hline $\begin{array}{l}\text { Nilai ekonomi ikan } \\
\text { (Desirability/Value of the fishery) }\end{array}$ & Nilai ekonomi ikan & Nilai produksi & $\begin{array}{l}\text { In-situ/ } \\
\text { Quisioner }\end{array}$ \\
\hline $\begin{array}{l}\text { Dampak perikanan pada ekosistem } \\
\text { (Fishery Impact to essential fish } \\
\text { habitat) }\end{array}$ & Kulitas Habitat & Distribusi dan habitat & $\begin{array}{l}\text { In-situ/ } \\
\text { Quisioner }\end{array}$ \\
\hline
\end{tabular}

Sumber: Patrick et al. (2009) 
Analisis kerentanan dari parameter produktivitas dan susceptibilitas (keterancaman) menggunakan pendekatan skoring. Setiap parameter memiliki skor bobot parameter, skor atribut, dan skor kualitas data (NOAA, 2009). Skor dari bobot berkisar antara 0-4 dimana $(0=$ tidak penting; $1=$ kurang penting; $2=$ penting; $3=$ lebih penting; 4=sangat penting. Skor atribut produktivitas antara 1-3 dimana (1=rendah; 2=medium; 3=tinggi) dan skor susceptabilitas juga dalam skala 1-3 dimana skor (1=rendah; $2=$ sedang; dan 3 tinggi). Skor kualitas data antara 1-5 dimana skor (1=data banyak dan lengkap; 2=data terbatas (temporal/spasial); 3=data menggunakan pendekatan pada genus atau family; 4=data tersedia pada informasi yang belum dipublish seperti di web/blog/paper dan materi presentasi dan $5=$ tidak ada data yang menjelaskan. Skor atribut dari setiap spesies kemudian dapat ditampilkan dalam plot scater x-y. Secara keseluruhan rata-rata produktivitas tergolong tinggi apabila rata-rata skor besar atau sama dengan 3 , dan rendah sama dengan 1 . Begitu juga susceptabilitas tergolong rendah bila mendekati skor 1 dan tinggi mendekati atau sama dengan 3 . Skor kerentanan secara keseluruhan (v) dari stok di hitung menggunakan persamaan jarak Euclidean dengan formulasi sebagai berikut (Patrick et al., 2009):

$$
V=\sqrt{(p-3)^{2}+(s-1)^{2}}
$$

Dimana; V = Indek vulnerability

$\mathrm{P}=$ Skor indek produktivitas

$\mathrm{S}=$ Skor indek suceptabilitas

Selanjutnya Patrick et al. (2009) menetapkan batasan nilai hasil analisis kerentanan (vulnerability) yaitu nilai skor 1,8. Apabila skor kerentanan besar $(>1,8)$, maka dapat diasosiasikan stok mengalami tekanan dan kerentanan yang tinggi atau potensial terjadi overfishing. Apabilai nilai skor kecil dari $(<1,8)$ bisa terjadi karena productivity tinggi atau suspectability rendah, sehingga potensi overfishing rendah. Sedangkan nilai vulnerability score diberikan sesuai hasil analisis masing-masing parameter yang dibandingkan dengan kategori yang berada dalam software PSA dari NOAA yang dikembangkan Patrick et al. (2009).

\section{HASIL DAN PEMBAHASAN}

\section{Hasil}

Kajian produktivitas perikanan bycatch tuna dari Sendang Biru Malang difokuskan pada tiga jenis ikan bycatch utama yaitu ikan baby tuna (Thunnus albacares), ikan cakalang (Katsuwonus pelamis), dan ikan lemadang (Coryphaena hippurus) selain sea turtle (Bertram et al., 2010). Ikan baby tuna yang tertangkap umumnya berukuran 300-420 mm, ikan cakalang 35-562 $\mathrm{mm}$ dan ikan lemadang berukuran 650-915 mm. Jenis-jenis ikan yang dikaji terlihat pada Gambar 2.

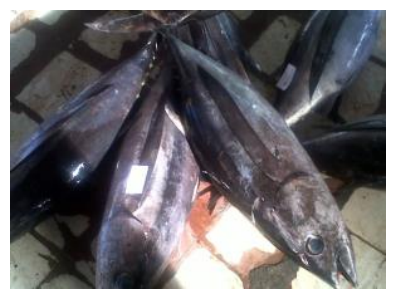

A

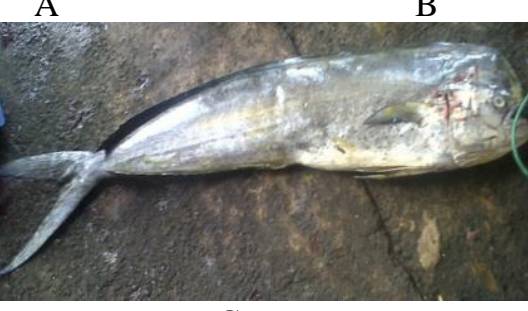

C

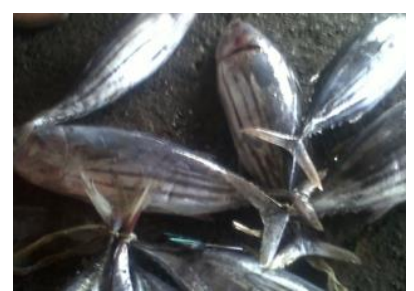

B
Gambar 2. Jenis ikan bycatch tuna Baby tuna (A), Cakalang (B) dan Lemadang (C)

Penilaian produktivitas diantaranya menggunakan data ukuran maksimum, koefisien pertumbuhan, pertama kali matang gonad, umur maksimum, fekunditas, kematian alami, rekruitmen, dan tingkat trofik level. Hasil perhitungan nilai setiap parameter dari ketiga jenis ikan tersebut disajikan pada Tabel 2.

Panjang maksimum ikan baby tuna adalah sekitar 73,02 cm, laju koefisien pertumbuhan (k) sebesar 0,91 per tahun, umur maksimum yang dapat dicapai 9 tahun. Pengaruh produksi terlihat dari laju pertumbuhan intrinsik (produksi) sebesar 1,42 dan fekunditas mencapai lebih dari $10^{4}$, namun baby tuna tidak ada yang matang gonad. Ikan tuna memijah satu kali dalam setahun dan telurnya tersebar dimana ikan tuna mengeluarkan semua telurnya dalam satu kali musim pemijahan. Tingkat kematian alami 0,69/tahun, dan kematian akibat penangkapan mencapai $0,85 /$ tahun atau sekitar $85 \%$. Kemampuan penambahan individu baru atau (tingkat rekruitmen) sebesar 20,6\% per tahun, dan pertama kali akan memijah pada umur 1,5 tahun. Little tuna ( $T$. albacares) akan 
mencapai panjang maksimum mencapai $240 \mathrm{~cm}$, dengan laju pertumbuhan 0,3/tahun, umur maksimum 6,5 tahun, umur mulai matang gonad 2,4 tahun, dan panjang saat matang gonad $56 \mathrm{~cm}$ (Fredou et al., 2016). Jenis yang lain seperti Yellowfin tuna tumbuh lebih lambat, umur mencapai 10 tahun dan mulai matang sexual 2,8 tahun dan dan memijah sepanjang tahun (Davies et al., 2015). Tingkat fekunditas T. albacores hampir sama dengan kelompok little tuna dengan fekunditas berada pada kisaran 17.814-560.792 butir telur dengan rata-rata 109.807 butir (Ardelia et al., 2016).

Ikan cakalang (skipjack) memiliki panjang maksimum sekitar sekitar 56,28 cm, koefisien pertumbuhan $(\mathrm{k})$ nya sebesar 0,88 per tahun. Fekunditas ikan cakalang sekitar 217.272320.230/ spawning, memijah satu kali selama musim pemijahan. Reproduksi skipjack diketahui parsial spawner setelah beberapa waktu tertentu di timur pantai barat Afrika (Andrade dan Santos, 2004). Tingkat kematian adalah 0,72 , dengan persentase rekruitmen diperoleh sebesar 20,8, dan pertama kali memijah pada umur sekitar 1,3 tahun. Skipjack tuna hidup sampai 4-5 tahun, tumbuh cepat, mencapai matang gonad pada umur 1,8 tahun dan memijah sepanjang tahun (Davies et al., 2015). Skipjack dominan tertangkap dengan purse seine $(38 \%)$, gillnet $(36 \%)$, pole and line 17\% dan lainnya 9\% (Davies et al., 2015).

Ikan lemadang (Coryphaena hippurus), memiliki panjang maksimum sekitar $91,45 \mathrm{~cm}$, koefisien pertumbuhan $(\mathrm{k})$ sebesar 1,4 per tahun. Umur maksimum ikan lemadang pendek dibanding lainnya yaitu 4 tahun. Menurut Fredou et al. (2016). Panjang maksimum $\left(\mathrm{L}_{\max }\right)$ ikan Lemadang (C. hippurus) $180 \mathrm{~cm}$, dengan laju pertumbuhan $0,72 /$ thn. Umur maksimum mampu dicapai 1,8 tahun dan panjang saat matang gonad $51 \mathrm{~cm}$. Laju pertumbuhan intrinsik (r) sekitar 3,86 dengan jumlah fekunditas antara 47.1931.422 .112 butir. Fekunditas ikan lemadang (Mahimahi) sangat tinggi variasinya, tergantung pada kondisi oksigen, suhu pada fase embryonic dan pemijahan (Pasparakis et al., 2016). Ikan lemadang memijah satu kali dengan persentase kematian alami ikan lemadang sebesar 0,85. Coryphaena hippurus tersebar dari Atlantic, Pacific dan India Ocean (Chang and Mander, 2012). Panjang total tercatat $238 \mathrm{~cm}$ (Lasso and Zapata, 1999), dengan umur maksimum 4 tahun (Schwenke and Buckel, 2008). Dugaan mencapai matang gonad pertama kali pada $50 \%$ yaitu ukuran 45,7-54,5 cm untuk betina dan 47,6-61,8 $\mathrm{cm}$ untuk jantan. Alat tangkap pancing dengan tali nilon dapat meningkatkan catchability dan mortality (Afonso et al., 2012). Tingkat rekruitmen sebesar $25,78 \%$, dan pertama memijah pada umur sekitar 0,4 tahun. Ikan ini termasuk ikan yang cepat matang gonad dan pertumbuhannya cepat. Ketiga jenis ikan ini termasuk kelompok ikan karnivora dan memiliki umur yang relatif panjang dari ikan herbivora. Ikan cakalang memiliki ukuran maksimum yang relative pendek, namum memiliki laju pertumbuhan yang besar. Artinya kan ini akan mencapai matang gonad lebih cepat dibandingkan jenis ikan lainnya.

Tabel 2. Parameter produktivitas baby tuna, cakalang, dan lemadang

\begin{tabular}{lccc}
\hline Parameter & Baby tuna & Cakalang & Lemadang \\
\hline Pertumbuhan Instrisik (Intrinsic growth) & 1,42 & 2,26 & 3,86 \\
Umur Maksimum (Max age) & $9 *$ th & $12 *$ th & $4 *$ th \\
Ukuran Maksimum (Max size) & $730,28 \mathrm{~mm}$ & $562.8 \mathrm{~mm}$ & $914,55 \mathrm{~mm}$ \\
Koefisien laju pertumbuhan/K (Growth & 0,91 & 0,88 & 1,4 \\
coefficient) & 0,69 & 0,72 & 0,85 \\
Kematian alami/M (Natural mortality) & $>10^{4 *}$ butir & $217.272-320.230$ butir & $47.193-1.422 .112$ \\
Fekunditas (Fecundity) & 1 (Total Spawner) & 1 (Total Spawner) & $1($ Total Spawner) \\
Strategy pemijahan (Breeding strategy) & $20,16 \%$ & $20.08 \%$ & $25.78 \%$ \\
Pola recruitment (Rekruitmet pattern) & 1,5 th & 1,3 & 0,4 \\
Umur saat matang gonad (Age at Maturity) & 4,3 & 3,8 & 4,4 \\
Rata-rata tropic level (Mean tropic level) & \multicolumn{2}{c}{} \\
\hline
\end{tabular}

\footnotetext{
*) Froese dan Pauly (2020)
} 
Susceptabilitas merupakan faktor kerentanan atau kelemahan karen ada interaksi dengan ekosistemya. Parameter susceptabilitas dievaluasi dan parameter strategi manajemen yang dilakukan saat ini, pendugaan rasio mortalitas penangkapn terhadap kematian alami alami, tingkah laku spesies seperti perilaku "schooling". Pola migrasi musiman serta tingkat "catchability" dari stok, kemudian proses penangan ikan setelah penangkapan, dan selektifitas dari alat tangkap. Secara umum ikan baby tuna, cakalang dan lemadang belum sepenuhnya diatur secara detail. Ikan ini relatif hidup bergerombol dan menetap pada area yang hampir sama. Hanya saja gerombolan ikan lemadang lebih kecil jumlahnya. Ikan baby tuna, cakalang dan lemadang juga memiliki rasio laju penangkapan yang tinggi terhadap kematian alami. Namun karena kegiatan penangkapan yang jauh dari perairan terbuka dan tidak mempengaruhi ekosistem. Hasil penilaian parameter susceptabilitas disajikan pada Tabel 3.

Rogan dan Mackey (2007) mencatat bahwa di NE Atlantic kelompok megafauna yang banyak tertangkap adalah skipjack, baby tuna, dan lemadang. Perikanan tuna yang menggunakan alat tangkap purse seine sebagian besar menangkap ikan yang mengelompok (schooling) seperti spesies skipjack (Katsuwonus pelamis), yellowfin (Thunnus albacares) dan big eye tuna (Davies et al., 2015). Dampak ketahan hidup setelah penangkapan (impact survival after capture) tidak hanya karena respon adaptasi tetapi karena jenis mata pancing (Huang et al., 2016). Perubahan jenis alat pancing dari model $\mathrm{J}$ menjadi $\mathrm{O}$ (lingkaran) meningkatkan kemampuan survival bycatch dan menurunkan kematian post release (Asch et al., 2018).

Sekitar 20-30\% sword fish hidup hidup saat handling dan kemdian berubah kearah kematian, yang memerlukan adaptasi dari bycatch (Carruthers et al., 2009). Penurunan bycatcth menjadi dasar bai EBFM (Ecosystem Based Fisheries Approach) untuk mengetahui tingkat resiko terhadap sumberdaya (Hahlbeck et al., 2017). Migrasi dan perubahan makanan dapat berpengaruh terhadap vulnerability pada Thunus allalungga (Williams et al., 2015). Peningkatan resiko dapat terjadi karena banyak jenis dan tipe alat yang digunakan dalam area secara bersamaan (Riskas et al., 2016). Pembatasan jumlah bycatch untuk spesies ikan bermigrasi bisa dilakukan dengan pendekatan tingkat kumulatif mortalitas menyangkut batasan potensi biologi yang dipindahkan (PBR) karena penangkapan (Riskas et al., 2016). Tekanan terhadap bycatch tuna juga dapat terjadi karena recreational fishing, yang menurunkan diversity dan jumlah tangkapan seperti Coryphaena hippurus dan Thunus allalungga NW Mediteranean (Lloret et al., 2008).

\section{Skor Atribut Produktivitas}

Bobot dari parameter atribut ditetap 2 yaitu skor setiap parameter dan skor rata-rata. Sebagian besar data baby tuna tergolong memiliki data dengan kualitas baik termasuk cakalang dan lemadang. Hasil penilaian skor untuk masingmasing jenis ikan disajikan pada Tabel 3.

Skor bobot dari ikan baby tuna, cakalang dan lemadang rata-ratanya sebesar 2 yang artinya semua parameter memiliki kepentingan yang sama. Skor atribut ikan baby tuna sebesar $(2,5 \pm 0,71)$ dan memiliki produktivitas yang tergolong tinggi karena lebih dari 2,5. Sementara itu terdapat sedikit perbedaan kualitas data yaitu untuk ikan baby tuna $(2,5 \pm 1,58)$, ikan cakalang $(2,20 \pm 1,55)$ dan lemadang $(2,20 \pm 1,55)$.

Proses handling yang baik saat operasi penangkapan seperti tidak menggunakan benda tajam dalam proses pemindahan dapat mengurangi laju mortalitas dan kondisi kritis dan kerentanan tuna (Gilman et al., 2014).

Selain longline, tradisional tuna traps (Tonnare) juga menangkap banyak bycatch terutama Sardinia (Storai et al., 2011). Efek climate change (Cheung et al., 2009) yang dapat diketahui dari perubahan life history juga dapat digunakan untuk mengetahui kerentanan dan potensi kolaps (Patrick et al., 2010) serta kepunahan spesies (Olden et al., 2008). Data yang mendukung riset ini tergolong cukup baik baik dari hasil pengamatan langsung maupun sumber lain yang dapat diandalkan. Koefisien produktivitas menunjukan bahwa tingkat produktivitas relatif tinggi.

\section{Skor Atribut Susceptabilitas}

Hasil evaluasi parameter susceptabilitas dari masing-masing ikan hasil tangkap sampingan perikanan tuna cukup beragam. Tabel 4 menyajikan skor atribut susceptabiliti yang diperoleh. Nilai skor ini kemudian menjadi analisis dari kerentanan ikan yang tertangkap saat penangkapan ikan tuna. 
Tabel 3. Parameter susceptabilitas ikan baby tuna, cakalang, dan lemadang

\section{Parameter}

Baby tuna

Management Strategy

Tumpang tindih area (Area overlap)

Daerah Sebaran geografis

(Concentrasi geografis)

Tumpang tindih vertical (Vertical overlap)

Rasio Mortalitas fishing terhadap alami (F / M)

Biomass stok pemijahan SSB

(spawning stock biomass)

Migrasi musiman (Seasonal migration)

Kelompok Berkumpul (Schooling aggregation)

Efek morphologi (Morfology affecting)

Kemampuan hidup setelah penangkapan (Survival after Capture)

Nilai ekonomi ikan

(Desirability/Value of the fishery)

Dampak perikanan pada ekosistem (Fishery Impact to essential fish habitat) dengan ikan tuna. area di WPP 573 lainnya.

1.24

$\mathrm{B}<25 \%$ dari $\mathrm{B} 0$ dengan tuna) memiliki harga yang tinggi.

\section{Cakalang} Stok target di Indonesia tidak memiliki batas atau $\begin{aligned} & \text { Stok target di Indonesia tidak memiliki } \\ & \text { batas atau belum ditetapkan. Kelompok }\end{aligned}$ belum dilakukan monitor secara baik. monitor secara baik.

$>50 \%$ dari stok tuna babi terjadi di area Tumpang tindih area terjadi antara 25\% penangkapan, karena memiliki niche yang sama sampai $50 \%$ dari stok yang ada di area penangkapan.

Stok Baby tuna terdistribusi dalam $>50 \%$ dari total Distribusi stok Cakalang lebih $>50 \%$ dari keseluruhan area in WPP 573

Lebih dari > 50\% dari stok (Tuna Baby) tersebar secara vertical dengan relung area penangkapan tok yang berada daerah penangkapan

1.39

B antara $25 \%$ sampai $40 \%$

Migrasi musiman tidak substantially

Migrasi musiman meningkatkan overlap dengan mempengaruhi overlapping dengan perikanan lainnya. (memiliki pola migrasi yang sama perikanan lainnya (kadang-kadang kita

masih temukan cakalang dalam jumlah yang sedikit)

Reson tingkah laku meningkat yang juga Respon tingkah laku meningkatkan mempengaruh catchability dari alat (tingkah laku catchability alat (tingkah laku schooling schooling meningkat peluangnya dan catchability) akan meningkatkan peluang tangkapan)

Species terlihat tingoi selectivitasnya terhadap alat Species terlihat tinggi selectivitasnya tangkap (morphology relative lengkap) terhadap alat tangkap (morphology relative lengkap)

$33 \%<$ perluang survivalnya dan $<67 \%$ (species $33 \%<$ perluang survivalnya dan $<67 \%$ (spesies ditemukan dalam kondisi hidup)

Stok sangat tinggi nilai ekonominya dan juga Stok sangat tinggi nilai ekonominya dan belum ditetapkan. Kelompok bycatch juga sama, bycatch juga sama, belum dilakukan

Relung vertical antara $25 \%$ dan $50 \%$ dari

\section{Lemadang}

Stok target di Indonesia tidak memiliki batas atau belum ditetapkan. Kelompok bycatch juga sama, belum dilakukan monitor secara baik.

Tumpang tindih area terjadi antara 25\% sampai $50 \%$ dari stok yang ada di area penangkapan.

Distribusi stok Cakalang lebih > 50\% dari keseluruhan area in WPP 573 yang bersamaan dengan cakalang

Relung vertical antara $25 \%$ dan $50 \%$ dari stok yang berada daerah penangkapan

1.73

B lebih > 40\% dari B0 (karena dari 10 yang ditemukan semua bertelur)

Migrasi musiman tidak substantially mempengaruhi overlapping dengan perikanan lainnya (kadang-kadang kita masih temukan Lemadang dalam jumlah yang sedikit)

Respon tingkah laku meningkatkan catchability alat (tingkah laku schooling akan meningkatkan peluang tangkapan)

Species terlihat tinggi selectivitasnya terhadap alat tangkap (morphology relative lengkap)

$33 \%<$ perluang survivalnya dan $<67 \%$ (species ditemukan dalam kondisi hidup)

Stok sangat tinggi nilai ekonominya dan juga memiliki harga yang tinggi. Tidak dampak yang merugikan, minimal atau berkala Tidak dampak yang merugikan, minimal (Alat tangkap menangkap selektif, hanya selektif, hanya dioperasikan di kolom ai dioperasikan di kolom air tanpa merusak habitat) $\quad$ tanpa merusak habitat)
Tidak dampak yang merugikan, minimal atau berkala (Alat tangkap menangkap selektif, hanya dioperasikan di kolom air tanpa merusak habitat) 
Tabel 4. Skor atribut produktivitas ikan baby tuna, cakalang dan lemadang

\begin{tabular}{|c|c|c|c|c|c|c|c|c|c|}
\hline \multirow[b]{2}{*}{ Productivity Attributes } & \multicolumn{3}{|c|}{ Baby Tuna } & \multicolumn{3}{|c|}{ Cakalang } & \multicolumn{3}{|c|}{ Lemadang } \\
\hline & $\begin{array}{c}\text { Bobot } \\
(1-4)\end{array}$ & $\begin{array}{c}\text { Skor } \\
\text { Atribut } \\
(\mathbf{1 - 3})\end{array}$ & $\begin{array}{c}\text { Skor } \\
\text { kualitas } \\
\text { data (1- } \\
5) \\
\end{array}$ & $\begin{array}{c}\text { Bobot } \\
(1-4)\end{array}$ & $\begin{array}{c}\text { Skor } \\
\text { Atribut } \\
(1-3)\end{array}$ & $\begin{array}{c}\text { Skor } \\
\text { kualitas } \\
\text { data (1-5) } \\
\end{array}$ & $\begin{array}{c}\text { Bobot } \\
(1-4)\end{array}$ & $\begin{array}{c}\text { Skor } \\
\text { Atribut } \\
(1-3)\end{array}$ & $\begin{array}{c}\text { Skor } \\
\text { kualitas } \\
\text { data (1- } \\
5 \text { 5) } \\
\end{array}$ \\
\hline Pertumbuhan Instrisik (Intrinsic growth) & 2 & 3 & 4 & 2 & 3 & 4 & 2 & 3 & 4 \\
\hline Umur Maksimum (Max age) & 2 & 3 & 4 & 2 & 2 & 4 & 2 & 3 & 4 \\
\hline Ukuran Maksimum (Max size) & 2 & 2 & 1 & 2 & 3 & 1 & 2 & 2 & 1 \\
\hline Laju pertumbuhan/K (Growth coefficient) & 2 & 3 & 1 & 2 & 3 & 1 & 2 & 3 & 1 \\
\hline Kematian alami/M (Natural mortality) & 2 & 3 & 1 & 2 & 3 & 1 & 2 & 3 & 1 \\
\hline Fekunditas (Fecundity) & 2 & 3 & 1 & 2 & 3 & 1 & 2 & 3 & 1 \\
\hline Strategy pemijahan (Breeding strategy) & 2 & 2 & 4 & 2 & 2 & 1 & 2 & 2 & 1 \\
\hline Pola rekruitment (Recruitment pattern) & 2 & 2 & 1 & 2 & 2 & 1 & 2 & 2 & 1 \\
\hline Umur saat matang gonad (Age at Maturity) & 2 & 3 & 4 & 2 & 3 & 4 & 2 & 3 & 4 \\
\hline Rata-rata tropic level (Mean tropic level) & 2 & 1 & 4 & 2 & 1 & 4 & 2 & 1 & 4 \\
\hline Rataan & 2 & 2.5 & 2.5 & 2 & 2.50 & 2.20 & 2 & 2.50 & 2.20 \\
\hline
\end{tabular}

Tabel 5. Skor atribut susceptabilitas ikan baby tuna, cakalang dan lemadang

\begin{tabular}{|c|c|c|c|c|c|c|c|c|c|}
\hline \multirow{2}{*}{ Atribut Susceptabilitas } & \multicolumn{3}{|c|}{ Baby Tuna } & \multicolumn{3}{|c|}{ Cakalang } & \multicolumn{3}{|c|}{ Lemadang } \\
\hline & $\begin{array}{c}\text { Bobot } \\
(1-4)\end{array}$ & $\begin{array}{c}\text { Atribu } \\
\text { t score } \\
(1-3)\end{array}$ & $\begin{array}{c}\text { Skor } \\
\text { quality } \\
\text { data (1-5) }\end{array}$ & $\begin{array}{c}\text { Bobot } \\
(1-4)\end{array}$ & $\begin{array}{c}\text { Atribut } \\
\text { score } \\
(1-3)\end{array}$ & $\begin{array}{c}\text { Skor } \\
\text { quality } \\
\text { data (1-5) }\end{array}$ & $\begin{array}{c}\text { Bobot } \\
(1-4)\end{array}$ & $\begin{array}{c}\text { Atribut } \\
\text { score } \\
(1-3)\end{array}$ & $\begin{array}{c}\text { Skor } \\
\text { quality } \\
\text { data (1-5) }\end{array}$ \\
\hline Manaement Strategi & 2 & 3 & 2 & 2 & 3 & 2 & 2 & 3 & 2 \\
\hline $\begin{array}{l}\text { Tumpang tindih area (Area } \\
\text { overlap) }\end{array}$ & 2 & 3 & 2 & 2 & 3 & 2 & 2 & 3 & 2 \\
\hline $\begin{array}{l}\text { Daerah Sebaran geografis } \\
\text { (Concentrasi geografis) }\end{array}$ & 2 & 1 & 2 & 2 & 1 & 2 & 2 & 1 & 2 \\
\hline $\begin{array}{l}\text { Tumpang tindih vertical } \\
\text { (Vertical overlap) }\end{array}$ & 2 & 3 & 2 & 2 & 3 & 2 & 2 & 3 & 2 \\
\hline $\begin{array}{l}\text { Rasio Mortalitas fishing } \\
\text { terhadap alami (F / M) }\end{array}$ & 2 & 3 & 1 & 2 & 3 & 1 & 2 & 3 & 1 \\
\hline $\begin{array}{l}\text { Kematian penangkapan } \\
\text { (Fishing mortality) }\end{array}$ & 2 & 1 & 1 & 2 & 2 & 1 & 2 & 3 & 1 \\
\hline $\begin{array}{l}\text { Biomass stok pemijahan SSB } \\
\text { (spawning stock biomass) }\end{array}$ & 2 & 3 & 1 & 2 & 2 & 1 & 2 & 1 & 1 \\
\hline $\begin{array}{l}\text { Migrasi musiman (Seasonal } \\
\text { migration) }\end{array}$ & 2 & 2 & 1 & 2 & 1 & 1 & 2 & 1 & 1 \\
\hline $\begin{array}{l}\text { Kelompok Berkumpul } \\
\text { (Schooling aggregation) }\end{array}$ & 2 & 3 & 1 & 2 & 3 & 1 & 2 & 3 & 1 \\
\hline $\begin{array}{l}\text { Efek morphologi (Morfology } \\
\text { affecting) }\end{array}$ & 2 & 3 & 1 & 2 & 3 & 1 & 2 & 3 & 1 \\
\hline $\begin{array}{l}\text { Kemampuan hidup setelah } \\
\text { penangkapan (Survival after } \\
\text { Capture) }\end{array}$ & 2 & 2 & 1 & 2 & 2 & 1 & 2 & 2 & 1 \\
\hline $\begin{array}{l}\text { Nilai ekonomi ikan } \\
\text { (Desirability/Value of the } \\
\text { fishery) }\end{array}$ & 2 & 3 & 1 & 2 & 3 & 1 & 2 & 2 & 1 \\
\hline $\begin{array}{l}\text { Dampak perikanan pada } \\
\text { ekosistem (Fishery Impact to } \\
\text { essential fish habitat) }\end{array}$ & 2 & 1 & 1 & 2 & 1 & 1 & 2 & 1 & 1 \\
\hline
\end{tabular}

Dari nilai skor diatas, nilai bobot dari parameter susceptabilitas ikan tuna, cakalang dan lemadang yaitu sebesar 2. Rata-rata skor atribut ikan baby tuna yaitu $(2,38 \pm 0,87)$, ikan cakalang $(2,30 \pm 0,85)$ dan ikan lemadang $(2,23 \pm 0,93)$. Sementara itu rata-rata kualitas data yaitu 1,30 yang tergolong cukup baik datanya.
Mengurangi kematian ikan bycatch akibat penangkapan yang sudah lebih dari 30\% harus dengan mengurangi fishing effort dan FAD (Kirby et al., 2014). Dalam upaya mendorong pengelolaan perikanan berbasis ekosistem, bycatch tidak boleh lebih dari 8\% (Kirby et al., 2014). Dalam tata kelola alat tangkap, purse seine dan longline merupakan alat utama yang juga 
menangkap baby tuna, sea turtle dan shark (Gilman, 2011). Alat tangkap purse seine dominan dominan menangkap baby tuna (Gilman, 2011). Dalam mitigasi bycatch selain mengurangi bycatch, juga perlu pengaturan metode penangkapandan pembatasan daerah penangkapan (Gillman, 2011). Tuna tropis menunjukan pola diet yang berbeda dalam ruang habitat secara vertical. Perubahan komposisi makanan lebih konsisten pada kondisi migrasi vertical dan horizontal. Perbedaan spasial dalam distribusi vertikal menunjukkan bahwa kerentanan $T$. albacores sangat dipengaruhi oleh letak geografis (Williams et al., 2015).

\section{Pembahasan}

Data life history sering digunakan untuk evaluasi pilihan antara konservasi ekosistem dan konservasi spesies (Fredou, 2012). Pemahaman tentang life history pada ikan target dan bycatch juga jadi pedoman dalam pengelolaan berbasis ekosistem dan sebagai pertimbangan bagi informasi kerentanan terhadap beban eksploitasi dan susceptibility terhadap penangkapan (Gilman et al., 2014). Dalam hal susceptibility species bycatch, masih terbatas data dari resiko kepunahan.

Tingkat kerentanan ikan bycatch tuna dari kedua atribut diatas yang dilakukan diperoleh nilai kerentanan dari ikan baby tuna adalah 1,66, ikan cakalang 1,27 dan 1,42 untuk ikan lemadang. Menurut Patrick et al. (2009) bahwa nilai kerentanan yang lebih besar dari 1,8 tergolong potensial overfishing. Berdasarkan kriteria tersebut dan hasil yang diperoleh dapat disimpulkan bahwa nilai kerentanan ketiga jenis ikan (baby tuna, cakalang, dan lemadang) masih kurang dari 1,8, yang berarti belum berpotensi overfishing. Nilai kerentanan tersebut tergolong tinggi karena sering ikan bycatch tertangkap lebih banyak dari ikan target. Untuk itu perlu diperhatikan tingkat pemanfaatannya bycatch tuna agar tidak terjadi tangkap lebih atau overfishing. Kondisi ini dapat berbahaya terutama terhadap baby tuna yang perlu dijaga agar menjadi dewasa untuk kemudian baru ditangkap. Hasil perhitungan dengan software PSA NOAA diperoleh nilai pada Tabel 6 .

Penangkapan mahi-mahi dengan jenis pancing berbentuk huruf $\mathrm{J}$ dan berbentuk hurup $\mathrm{O}$ tidak menunjukkan perbedaan hasil tangkapan yang nyata (Ward et al., 2009). Informasi discard juga digunakan untuk mengkaji informasi stok tuna, mitigasi dan menjamin hidup ikan kecil (Huang dan Liu, 2010). Apabila penangkapan tidak menimbulkan resiko yang ada mengacu pada laju tangkap antara 36-49\%, spawning biomass 90-98\%, spawning motality pada level 3-5\% dalam kondisi MSY (Pillig et al., 2016). Lebih 50\% dari Albacores dan 54\% dari Skippjack merupakan bycatch yang tertangkap dengan longline (Williams et al., 2015).

Secara keseluruhan data-data tentang produktivitas dan suceptabilitas dari ikan bycatch cukup baik kualitasnya. Skor kualitas data sebesar 1,3 menyatakan bahwa data input cukup baik sehingga hasil analisis dapat dijadikan gambaran tentang kondisi kerentanan ikan bycatch tuna di Sendang Biru. Sebaran data yang dianalisis dengan scatter plot ketiga jenis ikan tersebut seperti ditampilkan pada Gambar 2.

Nilai atribut skor relatif sama menunjukkan bahwa ikan ini memiliki interaksi yang kuat. Dengan kualitas data yang sama terdapat beberapa kemungkinan yang menyebabkan kerentanan berbeda. Karakteristik ikan lemadang yang relative sering terpisah dari schooling tuna dan cakalang bisa menjadi alasan rendahnya kerentanan mahi-mahi disbanding lainnya.

Penangkapan dan release menghasilkan dampak fisik yang dapat menurunkan pertumbuhan (Wilson et al., 2014) dan tolerasi resiko dari kematian setelah penangkapan. Fase mortality post capture dan lethal saat di dek kapal menunjukan pengauh negatif terhadap kesegaran ikan (Nilon). Squid banyak juga yang bycatch $(1,9 \%)$ dengan alat tangkap tuna purse seine (Olson et al., 2006). Penelitian tentang komposisi asam lemak memperlihatkan ada interaksi interpsesifik dalam jenis big eye tuna (BEY) dengan yellow fine tuna (YFT) serta skipjack (Sardene et al., 2016). Taiwan observer mencatat fishing mortality dengan longline tidak lebih dari 0,55/thn (Sun et al., 2002).

Hasil analisis kerentanan ikan diplotkan pada kurva hubungan produktivitas dan suceptabilitas dengan tampilan seperti Gambar 3. Pada Gambar 3, jika titik berada di dalam garis berwarna biru menunjukan batas aman dari risiko kerentanan. Sedangkan garis berwarna hijau menujukan batas moderate dari risiko dan merah garis yang menunjukan berisiko tinggi.

Gambar 3 menjelaskan bahwa ikan cakalang dan lemadang nilai produktivitasnya lebih tinggi dibandingkan dengan nilai susceptabilitasnya, sehingga belum beresiko terjadi overfishing. Namun untuk ikan baby tuna nilai susceptabilitasnya lebih tinggi jika dibanding dengan produktivitasnya, sehingga harus berhatihati agar tidak terjadi overfishing. Meningkatnya kerentanan baby tuna tidak mempengaruhi proses 
recruitment baby tuna, tapi mempengaruhi kemampuan pulih atau resiliensinya tuna dewasa. Jika kemampuan resilience tuna dewasa rendah secara otomatis akan mengarah pada kondisi rentan. Untuk mengantisipasi terjadinya penurunan kualitas tuna dewasa maka dapat dilakukan pengendalian penangkapan baby tuna.

Tabel 6. Tingkat kerentanan ikan baby tuna, cakalang, dan lemadang

\begin{tabular}{lccccc}
\hline \multirow{2}{*}{ Stok } & \multicolumn{2}{c}{ Produktivitas } & \multicolumn{2}{c}{ Suceptabilitas } & \\
\cline { 2 - 5 } & $\begin{array}{l}\text { Skor atribut } \\
\text { produktivitas }\end{array}$ & $\begin{array}{l}\text { Skor kualitas data } \\
\text { produktivitas }\end{array}$ & $\begin{array}{l}\text { Skor atribut } \\
\text { suceptabilitas }\end{array}$ & $\begin{array}{l}\text { Skor kualitas data } \\
\text { suceptabilitas }\end{array}$ & Kerentanan \\
\hline Baby Tuna & 2,5 & 2,8 & 2,58 & 1,33 & 1,66 \\
Cakalang & 2,5 & 2,8 & 2,33 & 1,33 & 1,42 \\
Lemadang & 2,5 & 2,8 & 2,17 & 1,33 & 1,27 \\
\hline
\end{tabular}

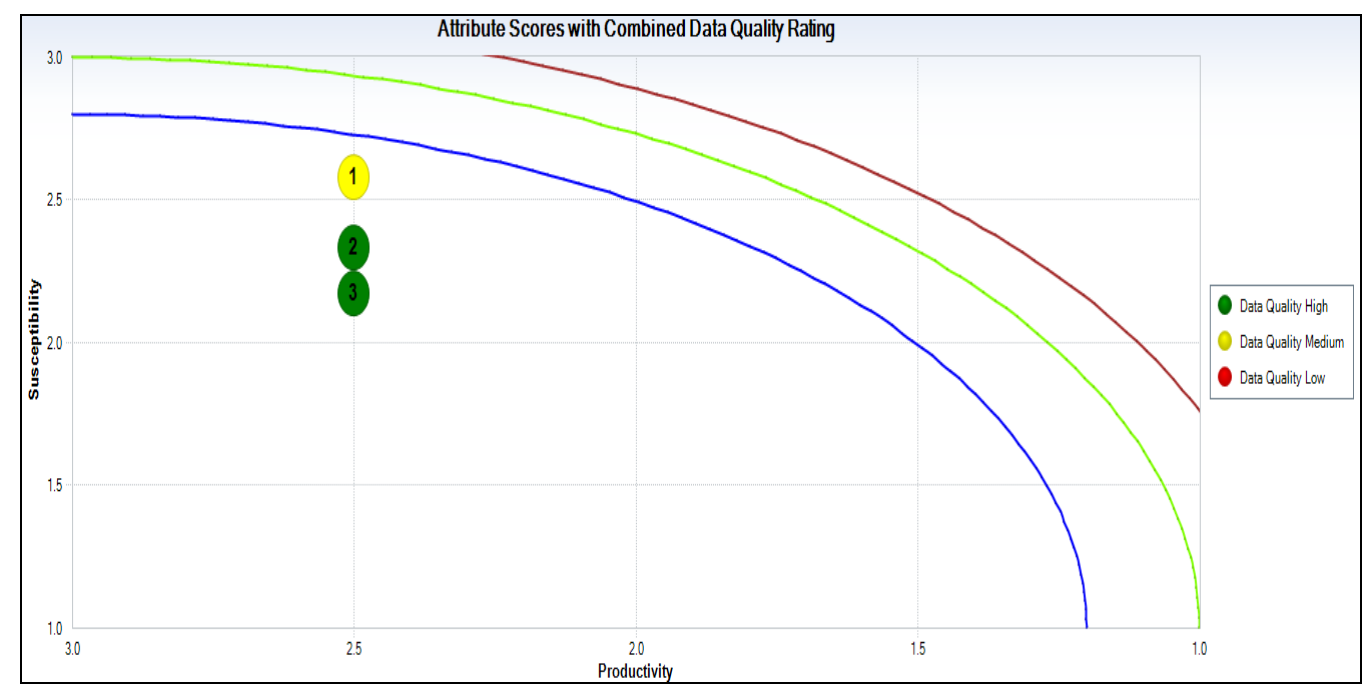

Gambar 3. Vulnerability ikan baby tuna (1) cakalang (2), dan lemadang (3)

Peningkatan kerentanan cakalang dipengaruhi musiman dan beberapa faktor lingkungan seperti kedalaman dan termoklin (Andrade dan Santos, 2004). Jenis yellowfin, skipjack, dan big eye tuna berbeda level susceptabilitasnya, overfishing, variasi laju tumbuh, umur pada saat matang gonad, dan daerah pemijahan (Davies et al., 2015). Fredou et al. (2017) menemukan bahwa produktivitas Thunus albacores 2,63, Coryphaena hippurus 2,471, dan Katsuwonus pelamis 2,471. Tingkat susceptabilitas Thunus albacores 2,63, Coryphaena 2,09, dan Katsuwonus pelamis 2,143. Nilai skor kerentanan dari Thunus albacores 2,28, Coryphaena hippurus 1,213, dan Katsuwonus pelamis 1,26. Berdasarkan kriteria kerentanan menurut NOAA, bahwa kerentanan Thunnus albacares tergolong tinggi, Coryphaena hippurus dan Katsuwonus pelamis tergolong rendah. Menurut family, kelompok Coryphaenidae kerentananya 1,46 dan Scombridae 1,74 yang sama sama rendah. Sedangkan menurut sebaran wilayah keretanan di Samudera Atlantik lebih tinggi dari Samudera Hindia. Suryaman et al., (2017) memperoleh nilai kerentanan tuna neritik berturut-turut untuk ikan tenggiri 1.25, tongkol krai 1.37 , tongkol abu-abu 0.91, tongkol komo
1.49, dan tongkol lisong 1.41 di Pelabuhanratu. Hasil ini menunjukkan bahwa secara umum masih tergolong resiko dan rentan rendah. Sehingga dalam proses penangkapan tidak perlu dilakukan penambahan upaya tangkap, yang dapat memacu peningkatan tekanan. Namun diperlukan pengaturan Batasan kuota ikan bycatch yang diperbolehkan agar tidak mengarah pada eksploitasi.

\section{KESIMPULAN}

Penangkapan bycatch saat ini masih tergolong aman dan belum beresiko rentang, namun dalam jangka panjang bersamaan dengan menurunnya ikan tuna, dapat menyebabkan terjadinya kerentanan yang lebih besar pada kelompok ikan sampingan. Karena secara umum biasanya kelompok ikan baby tuna tetap menjadi hasil tangkapan saat ikan tuna besar tidak tertangkap. Secara umum risk (resiko) kerentanan masih rendah dari batasan skor yaitu 1,8 dan stok masih berpotensi berkelanjutan. Ikan tangkapan bycatch perikanan tuna di Sendangbiru harus dapat dikelola dengan baik agar tetap berkelanjutan.

Saran dari penelitian ini adalah perlu dikembangkan proses pendekatan alat tangkap 
atau proses penangkapan yang tidak menyebabkan tinggi resiko bycacth tertangkap terutama dari kelompok ETP, serta pengawasan secara berkala terhadap proses penangkapan ikan tuna yang juga menangkap bycatch. Observer di Taiwan (Huang, 2011) melakukan edukasi pada nelayan tuna untuk mengurangi penangkapan bycatch.

\section{UCAPAN TERIMA KASIH}

Pada kesempatan ini penulis mengucapkan terima kasih kepada WWF-Indonesia yang telah memberikan dukungan dalam pelaksanaan pengumpulan data bagi penyelesaian penelitian ini dan diperkenankannya untuk dipublikasikan dalam jurnal ilmiah. Selain itu juga kepada seluruh tm yang terlibat dalam proses pengumpulan datanya dilapangan.

\section{DAFTAR PUSTAKA}

Ardelia V, Yonvitner, Boer M. 2016. Biologi reproduksi ikan tongkol Euthynnus affinis di Perairan Selat Sunda. Jurnal Ilmu dan Teknologi Kelautan Tropis. 8(2):689-700.

Asch RG, Cheung WWL, Reygondeau G. 2018. Future marine ecosystem driver, bioiversity and fisheries maximum catch potential in Pacific Island Country and toritories under climate change. Marine Policy. 88:285-294.

Afonso AS, Santiago R, Hazin H, Hazin FHV. 2012. Shark by catch and mortality and hooks bite-offs in pelagic longlines. interaction between hook type and leader material. Fisheries Research. 131-133:914.

Andrade HA, Santos JAT. 2004. Seasonal trend in the recruit at of skipjack tuna (Katsuwonus pelamis) to the fishing ground in the south west Atlantic. Fisheries Research. 66:185-194.

Bertram PK, Kaneko JK, Nakamura KK. 2010. Sea turtle bycatch to fish cacth rasio for differentiating hawai longline caught seafood product. Marine Policy. 34:145149.

Carruthers EH, Schneider DC, Neilson JD. 2009. Estimating the odds of survival and ientifying mitigation opportunities for common bycatch in pelagic longline fisheries. Biological Conservation. 142:2610-2630.

Chang SK, Maunder MN. 2012. Aging material matters in the estimation of van bartallanfy growth parameter for dolphinfish
(Coryphaena hippurus).

Fisheries

Research. 119-120:147-153.

Cheung WW, Lam VW, Sarmiento JL, Kearney K, Watson R, Pauly D. 2009. Projecting global marine biodiversity impacts under climate change scenarios. Fish and fisheries. 10(3):235-251.

Davies TK, Mees CC, Milner EJ, Gulland. 2015. Second guesing uncertainty: scenario planning for management of The Indian Ocean tuna purse seine fisheries. Marine Policy. 62:169-177.

Fredou FL, Kell L, Fredou T, Gaertner D, Potier M, Bach P, Travassos P, Hazin F, Menard F. 2016. Life History traits and fishery pattern of teleost caught by the tuna longline in the South Altantic and Indian Ocean. Fisheries Research. 179:308-310.

Fredou FL, Kell L, Fredou T, Gaertner D, Potier M, Bach P, Travassos P, Hazin F, Menard F. 2017. Vulnerability of teleost caught by the pelagic tuna longline fleet in South Atlantic and Western Indian Oceans. Deep-Sea Research II. 140:230-241.

Froese R, Pauly D. Editors. 2020. World Wide Web electronic publication. FishBase.

Gilman EL. 2011. Bycatch governance and best practise mitigation technology in global tuna. Marine Policy. 35:590-609.

Gilman E, Owen M, Kraft T. 2014. Ecological risk assesement of The Marshall Island longline tuna fishery. Marine Policy. 44(14):239-255.

Hahlbeck N, Scales KL, Dewan H, Maxwell SM, Bograd SJ, Hazen EL. 2017. Oceanographic Determinant of ocean sunfish (mola-mola) and bluefin tuna (Thunnus orientalis) bycatch pattern in the california large mesh size drift gilnet fishery. Fisheries Research. 191:154-163.

Hermawan D, Boer M, Dahuri R, Budiharsono S, Ma'ruf WF. 2012. Ikan tuna sirip kuning (Thunnus albacores) di perairan zona ekonomi eksklusif Indonesia Samudera Hindia Selatan Jawa Timur. Jurnal Harpodon Borneo. 5(1):1-11.

Huang HW. 2011. Bycatch of high sea longline fisheries and measures taken by Taiwan: action and challangge. Marine Policy. 35:712-720.

Huang HW, KM Liu. 2010. Bycatch and discard by taiwanese large scale tuna longline in the Indian Ocean. Fisheries Research. 106:261-270. 
Huang HW, Swimer Y, Bigelow K, Guiterez A, Foster DG. 2016. Infulence of hand type on catch of comercial and bycatch species in an Atlantic tuna fisheries. Marine Policy. 65:68-75.

KKP 2014. Peraturan Menteri Kelautan dan Perikanan No 18 tahun 2014 tentang Wilayah Pengelolaan Perikanan Republik Indonesia. Jakarta.

Lloret J, Zaragoza N, Cabalero D, Riera V. 2008. Biological and socioeconomic implication of recreational boat fishing for the management of fishing resources in The Marine Reserve of Cap de Creus (NW Mediteranian). Fisheries Research. 91:252-259.

Lasso J, Zapata L. 1999. Fisheries and biology of Coryphaena hippurus (Pisces: Corypahenidae) in The Pacific Coast of Colombia and Panama. Sci. Mar. 63:387399.

Kirby DS, Visserm C, Hanich Q. 2014. Assesement of eco-labelling schemes for pacific tuna fisheries. Marine Policy. 43:132-142.

Sunoko R, Huang HW. 2014. Indonesia tuna fisheries development and future strategy. Marine Policy. 43:174-183.

Olson RJ, Roman-Verdesoto MH, Macias-Pita GL. 2006. Bycatch of jumbo squid Dosidicus gigas in the tuna purse seine fishery of the eastern Pacific Ocean and predatory behavior during capture. Fisheries Research. 79(200):48-55.

Olden JD, Kennard MJ, Pusey BJ. 2008. Species invasions and the changing biogeography of Australian freshwater fishes. Global Ecology and Biogeography. 17(1):25-37.

Pillig GM, Berger AM, Reid C, Harley SJ, Hampton J. 2016. Candidate biological and economic target reference point for the South Pacific albacore longline fisheries. Fisheries Research. 174:167-178.

Puspita R, Boer M, Yonvitner. 2017. Tingkat kerentanan ikan tembang (Sardinella fimbriata, Valenciennes 1847) dari kegiatan penangkapan dan potensi keberlanjutan di perairan Selat Sunda. Jurnal Pengelolaan Perikanan Tropis. 1(1):17-23.

Patrick WS, Spencer P, Ormseth O, Cope J, Field J, Kobayasi D, Gedamke T, Cortes E, Bigelow K, Overholtz W, Link J, Lawson P. 2009. Use of Productivity and Suceptability Indices to Determine Stock
Vulnerability, with Example Application ti six US Fisheries. UA Dept of Commerce, NOAA. $117 \mathrm{pp}$.

Patrick WS, Spencer P, Link J, Cope J, Field J, Kobayashi D, Lawson P, Gedamke T, Cortés E, Ormseth O, Bigelow K, Overholtz W. 2010. Using productivity and susceptibility indices to assess the vulnerability of United States fish stocks to overfishing. Fishery Bulletin. 108(3):305-322.

Pasparakis C, Mager EM, Stieglitz JD, Benneti D, Grosell M. 2016. Effect of deepwater horizon crude oil exposure, temperature, and developmental stage on oxygen consumption of embrionic and larval mahi-mahi (Corphaena hippurus). Aquatic Toxicology. 181:113-123.

Rogan E, Mackey M. 2007. Megafauna bycatch in driftnet for albacore tuna (Thunus allalungga) in the NE Atlantic. Fisheries Research. 86:6-14.

Riskas KA, Fuetes MMPB, Haman M. 2016. Justifyig the need for collaborative management of fisheries bycatch. a lesson from marine turtle in Australia. Biologycal Conservation. 196:40-47.

Sardenne F, Bodin N, Chassot E, Amiel A, Fouche E, Degroote M, Holanda S, Pethybridge H, Lebreton B, Guillou G, Menard F. 2016. Tropic niche of sympatric tropical tuna in Western Indan Ocean infered by stable isotop and neutral fatty acid. Pross in Oceanography. 146:75-88.

Sun CI, Ehrhardt NM, Porch CE, Yeh SZ. 2002. Analyses of yield and spawning stock biomass per recruit for the South Atlantic albacore. Fisheries Research. 56:193-204.

Storai T, Zinzula L, Repetto S, Zuffa M, Morgan A, Mandelman J. 2011. Bycatch of large elasmobranchia in the tradisional tuna traps (tonnare) of Sardinia from 19902009. Fisheries Research. 109(1):74-79.

Schwenke KL, Buckel JA. 2008. Age and growth of Coryphaena hippurus caught of the coast of North Carolina. Fish Bull. 106:8392.

Suryaman E, Boer M, Adrianto L, Sadiyah L. 2017. Analisis produktivitas dan suceptabilitas pada tuna neritik di Pelabuhanratu. Jurnal Penelitian Perikanan Indonesia. 23(1):19-28.

Ward P, Epe S, Kreutz D, Lawrence E, Robin C, Sands A. 2009. The Effect of Circle hooks $\mathrm{J}$ on bycatch and target catches in Austalia 
pelagic longline fisheries. Fisheries Research. 97:253-262.

Williams AJ, Allain V, Nicol SJ, Evans KJ, Hoyle SD, Dupoux C, Vourey E, Dubosc J. 2015. Vertikal behavior and diet of albacores tuna (Thunnus allalunga) vary with latitude in the South Pacific Ocean. Deep Sea Research. 11-113:154-169.

Wilson SM, Raby GD, Burnett NJ, Hinch SG, Cooke SJ. 2014. Looking beyond the mortality of bycatch. sub lethal effect of incidental capture on main animal. Biology Conservation. 171:61-71.

Yonvitner, Setyobudiandi I, Apriansyah, Hidayat DR. 2017a. Tropical eel: vulnerability approach untuk pengelolaan berkelanjutan.
Jurnal Pengelolaan Perikanan Tropis. 1(1):41-50.

Yonvitner, Setyobudiandi I, Fahrudin A, Affandi R, Riani E, Triramdani N. 2017b. Review indikator dari indek PSA NOAA untuk ikan pelagis kecil (tembang: Sardinella sp.; Famili Clupeidae) dan ikan demersal (kuris: Nemipterus sp.; Famili Nemipteridae). Jurnal Teknologi dan Manajemen Perikanan Laut. 8(8):123-135.

Yonvitner, LIoret J, Boer M, Kurnia R, Akmal SG, Yuliana E, Yani DE, Gómez S, Setijorini LE. 2020. Vulnerability of marine resources to small-scale fishing in a tropical area: The example of Sunda Strait in Indonesia. Fisheries Management and Ecology. 27(5):472-480. 